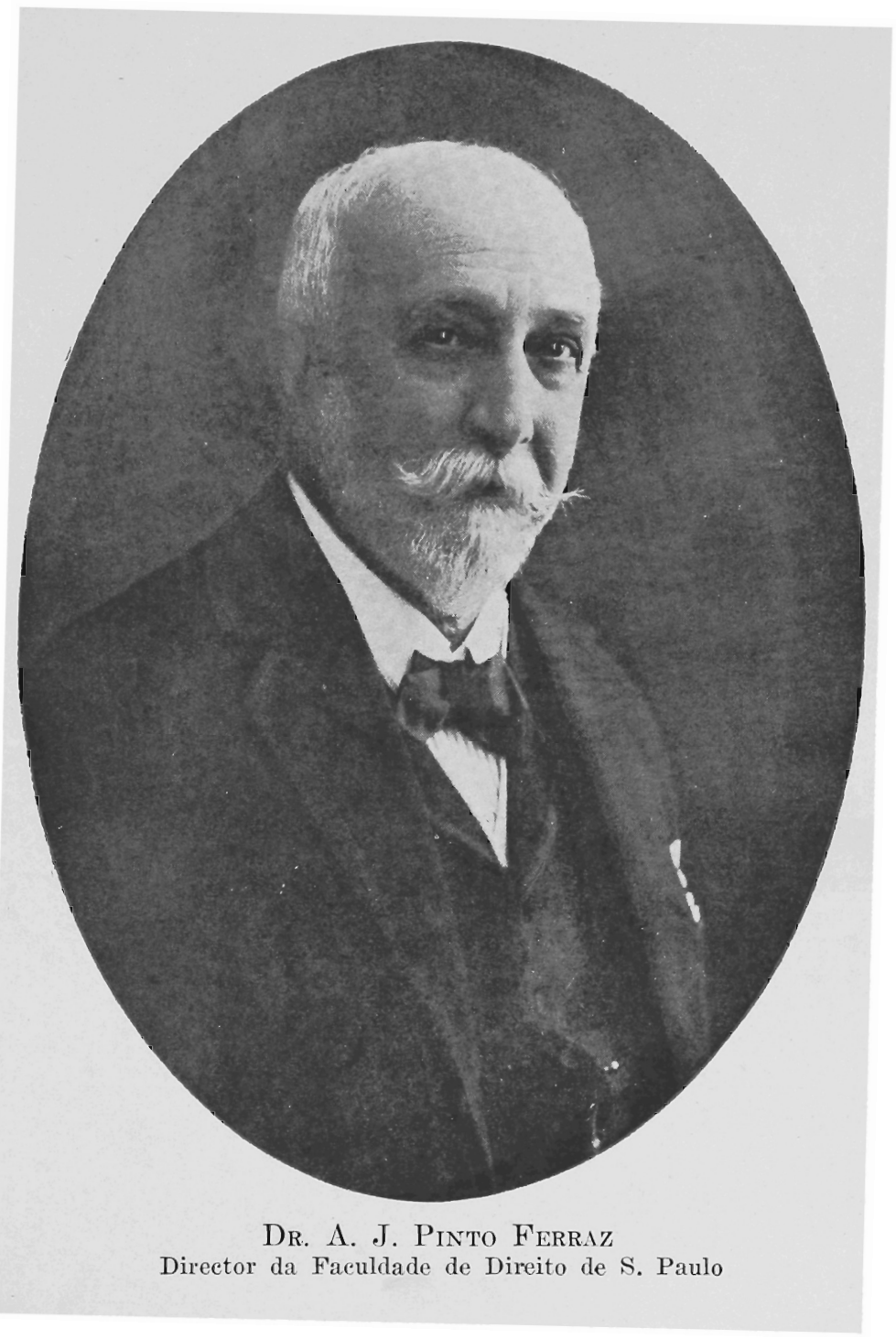





\section{CENTENARIO DA FACULDADE DE DIREITO}

Fundada a 11 de Agosto de 1827 completa este anno a Faculdade seu centenario.

Tem tido quem com seus fastos se occupasse. Mais do que chronistas foram os Professores Almeida Nogueira e Spencer Vampré. Ao 1." deve ella a obra interessantissima sob o titulo Tradições e Reminiscencias; ao 2. as Memorias para a Historia da Academia de São Paulo. - Em rapido retrospecto vamos dizer alguma coisa sobre o quẹ tem sido a vida dessa instituição, seus methodos de ensino, seu corpo docente, e as vicissitudes por que tem passado. - Conservaremos nesta breve chronica o costume de indicar as reformas pela data, ou pelos nomes de seus autores.

A Instituiçãa. - Desde 1827 até 19 de Ảbril de 1879, reforma Leoncio de Carvalho, conhecida tambem pelo nome de liberdade de ensino, só admittiam nossas leis as duas faculdades officiaes: de Recife e de São Paulo. A reforma permittiu a creação por particulares de outros institutos de ensino. Ninguem todavia se utilizou de tal permissão. Foi após a reforma Benjamin Constant que as Faculdades livres se desenvolveram fazen'do concurrencia ás officiaes no ensino. Em 1911, com a denominada lei Rivadavia, tentou-se a desofficialização das duas faculdades, e augmentaram-se as faculdades livres de modo extraordina- 
rio. Com muita reluctancia recebeu a Faculdade de São Paulo essa reforma. Era o professor Herculano de Freitas de opinião que o corpo docente deveria recusar:se a obedecer ao decreto, por haver o Governo excedido os limites da autorização do congresso legislativo. Outros entendiam ser contrária a lei ao art. 35 ns. 2 e 3 da Constituição Federal, porque abandonava a União um estabelecimento de ensino que não tinha meios para se manter. Prevaleceu entretanto a opinião de obediencia ao decreto, esperando melhores tempos, seguros os professores de que não poderia durar muito um tal regimen. Contrarios ao decreto foram particularmente os professores José Ulpiano, Porchat, João Mendes, Herculano de Freitas e João Arruda. Como era de esperar, em 1915 veio a reforma Carlos Maximiliano dar outra orientação ao ensino, restringindo o direito dos particulares sobre creação de Academias livres. Emfim a ultima reforma de 1925, a reforma João Luiz Alves, limitou ainda mais esse direito, de modo que hoje raras são as faculdades que se mantêm ao lado das officiaes, e taes estabelecimentos são rigorosamente fiscalizados. - Força é confessar que problema muito serio é este da officialização do ensino.

$\mathrm{Na}$ discussão de tão ardua questão, não tem apparecido sombra de cogitações de ordem publica. Quasi exclusivamente se tracta em taes disputas dos interesses dos creadores dos institutos. Parece que o debate deveria versar sobre a insufficiencia do ensino official, por exiguo ou atrazado; e a superioridade do ministrado nas faculdades livres: só assim se manteria na altura de materia de interesse publico. 
O Ensino. - Muitas têm sido as reformas no ensino a partir de 1871, reforma João Alfredo. Esta porém foi insignificante, embora huvesse provocado a celebre e tão desantada desordem academica cujas minucias todos nós conhecemos.

Indignaram-se os estudantes com a modificação no systema de exames, modificação aliás de importancia secundaria. De muito maior vulto foi a reforma de 19 de Abril de 1879 a que fizemos allusão acima: a do ensino livre.

Facultanido aos estudantes a frequencia livre, alterou profundamente o systema de jensino. Seus resultados foram desastrosissimos, mas o systema foi mantido até 1895. - Com o advento da republica veio a reforma Benjamin Constant alterar profundamente o ensino, dividindo o curso em series, de mado que houve, segundo as expressões vulgares, bachareis juristas, sociologos e notarios.

Reorganizou-se o corpo docente da Faculdade, de modo que ideas novas foram sustentadas das cathedras. Todos os lentes antigos foram afastados de suas cathedras com diversos pretextos. Em 1895 voltou-se á obrigatoriedade da frequencia, e consequentemente augmentou-se o rigor no estudo, por poder o mestre acompanhar de perto e constantemente o estudo do alumno. A reforma de 1901, Epitacio Pessoa, que alterou muito o programma de ensino, representa o producto de uma harmonia entre os exageros da reacção de 1891 e o antigo regimen. Só em 1911 veio a reforma Rivadavia subverter essa ordem de coisas, esta. belecendo as mais originaes providencias sobre o ensino. Foi acto governamental de quem não tinha nenhum co- 
nhecimento do que é o magisterio superior. Por isto mesmo não se manteve sinão durante o governo do marechal Hermes, sendo logo substituida pelo decreto 11.530, Carlos Maximiliano, que regeu até 1925, optima organização do ensino, si soffrer alguns retoques. A tão discutida rer forma João Luiz Alves, publicada em’ 1925, está ainda em observação. Reduziu as attribuições do corpo docente á funcção meramente didactica, limitou o numero de logares na matricula, tendo em attenção o augmento excessivo de bachareis em Direito, procurou afastar de suas cathedras os professores antigos, só deu entrada no corpo docente a moços, e accentuou a reofficialização da Faculdade. Só o tempo poderá dizer si foram acertadas essas medidas - Tomando em seu conjuncto o ensino desde 1827 até hoje, diremos que sempre teve a mesma maneira de ser ministrado: a classica das preleoções. Os exercicios dos éstudantes e seus exames variaram algum tanto. A principio houve as chamadas á licção e as sabbatinas. Estas decahiram desde o ensino livre. Constituiam, a nosso ver, valioso exercicio para a intelligencia e ao mesmo tempo eram uma excellente prova de estudo dada pelos alumnos, ou meio de fiscalização de tal estuldo pelos professores. Houve as dissertações, prova muito precaria, por dar occasião a abusos de estudantes menos escrupulosos, que confiavam a terceiros o trabalho, apresentando-o como proprio. A prova oral que era feita até 1871 sobre ponto tirado com antecedencia de 24 horas, passou, desde então, a ser realizada immediatamente após a tirada do ponto. Muito se tem criticado o espirito reaccionario dos professores. Si assim foi durante o tempo em que a cidade era 


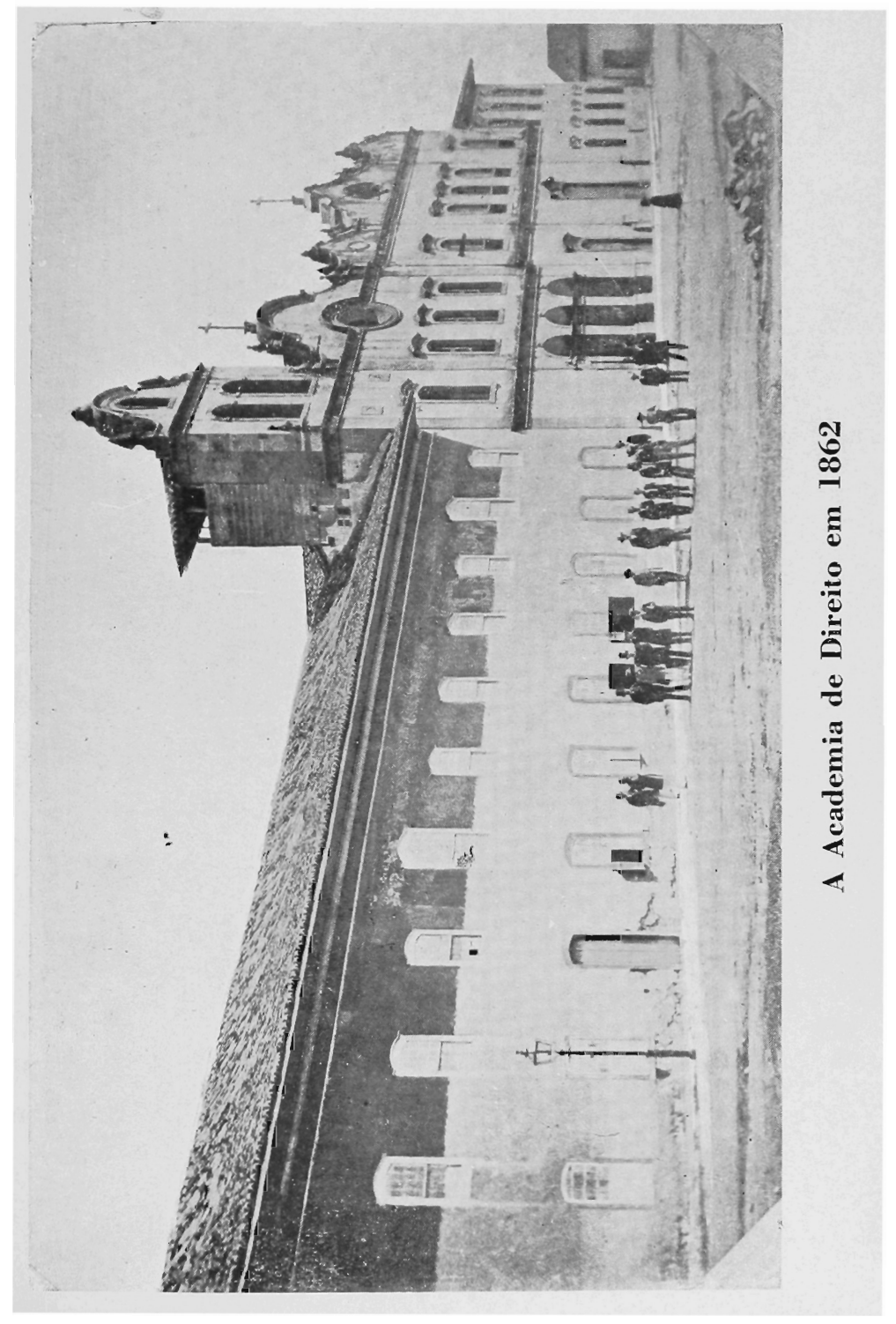



pequenissima, hoje, sendo quasi todos advogados, força lhes é acompanhar o movimento scientifico, para se manterem á altura das discussöes forenses. E' a vantagem de aproveitarem-se os advogados para o magisterio, vantagem, é certo, contrabalançada por serios inconvenientes, como abaixo diremos. - Pessoas pouco versadas no Direito falam muito em tornar o ensino practico. Isto é tudo quanto ha de mais absurdo. $O$ que se deve procurar e se tem procurado é tornar o ensino util, ministrando os principios fundamentaes que servirão mais tarde para o alumno se guiar em seu progresso, qualquer que seja o ramo de actividade a que venha entregar-se: diplomacia, notariado, advocacia ou magistratura. Bem traçaram os mestres a ligação intima entre a theoria e a practica, mostrando a impossibilidade de as separar. Foi dicto que a medição empirica das terras no Egypto deu origem ao conhecimento das linhas e figuras geometricas, donde a sciencia theorica e abstractas denominada Geometria; e que esta sciencia habilitou os practicos a dividirem com instrumentos exactissimos enormes regióes, a navegar com certeza mathematica, e a traçar estradas com direcção precisa e proveitosissimas para o trafego, sendo taes applicações feitas por homens ignorantes das altas verdades scientificas e exclusivamente practicos. São as verdades scientificas que habilitam o rude nauta a aproveitar-se do astrolabio ou do sextante, são ellas que tornam capaz de se utilizar do theodolito o agrimensor pouco versado em theoremas gerometricos, são as verdades philosophicas e sociologicas que habilitam os legisladóres a formularem preceitos artisticos que mantêm e desenvolvem as sociedades, são ellas que põem os arlvo- 
gados e juizes em condições de darem ás leis a applicação mais util para a vida social, e são ellas pois que devem ser objecto dos estudos academicos. - $\mathrm{O}$ desenvolvimento excepcional de São Paulo não podia deixar de exercer damnosa influencia sobre os estudos. Em uma pequena cidade, onde raras são as diversões muito mais tempo tem o rapaz para o estudo. Num centro populoso e agitado, barulhento e festivo, difficil é ao moço uma tranquilla applicação como a que tinham os da geração que não conhecia a opulencia da nossa capital.

O Corpo Docente. - Nos primeiros tempos até a proclamação da republica, a nomeação era feita pelo Governo á vista de uma lista triplice apresentada pela congregação. Sob o novo regimen, a maior attenção foi sempre ligada á classificação dada pela congregação, e pode ser dicto, sem temor de erro, haver sido a escolha exclusivamente da congregação, porque o Governo preferia o candidato collocado em ]. . logar na lista. A reforma João Luiz Alves veio emfim dar á congregação esse direito que ella já exercia. Só em uma hypothese ha a escolha do Governo, e é quando ha mais de um candidato com a mesma nota. Disse o dr. Pedro Lessa que a exigua remuneração attribuida aos professores pela lei deu em resultado sahirem elles da classe dos advogados, e serem muito numerosos. E' perfeitamente verdade. Seria de esperar que os professores pouca attenção dessem ào trabalho academico. Isto porém felizmente não aconteceu, e basta para prova mencionar os nomes do proprio Pedro Lessa es do actual Director de nossa Faculdade, advogados com serviço verdádeiramente colossal em nosso forro, e que foram optimos pro- 
fessores. Já antes, quando a aldvocacia era pouco rendosa em São Paulo, houve professores que honrariam qualquer faculdade europea, e que foram advogados procurados. Sirvam de exemplo José Bonifacio, Ramalho, Carrão, Chrispiniano Soares e Duarte de Azevedo. Todos esses tiveram sua attenção distrahida dos serviços academicos por importantes pleitos.

Os Directores. - Durante muito tempo foram da nomeação do Governo. Quando entrou em vigor o regimen Rivadavia, danło ás faculdades personalidade juridica, tornaram-se elles deı eleição da congregação. A reforma Carlos Maximiliano porém voltou ao antigo systema. Nem outra coisa poderia ser esperada, uma vez que a União passou de novo a sustentar a Faculldade. - Não podemos, occupando-nos com os Directores, deixar de dizer duas palavras sobre o actual. Nasceu em 2 de Julho de 1851, sendo descendente de nobilissima familia paulista. Bacharelou-se :em 1874, e defenileru brilhantemente theses em 1878. Em 1891 foi nomeado lente. Anteriormente, exercia a advocacia nesta capital podendo-se dizer que seu escriptorio era o unico que concorria com o do dr. João Mendes. Sabido era que si, em causa de vulto um litigante procurava ao dr. Mendes, o outro era forçado a valer-se das luzes do dr. Pinto Ferraz, unico emulo digno do celebre maranhense. Quando fez sua defesa de these, era voz corrente entre os alumnos que fôra o primeiro, de memoria da Faculdade, que verdadeiramente "defendêra, suas proposições ou theses" Sua technica, como bem dizem todos (Tradições 2/309 e Memorias 2/590), era realmente impercavel. Abeberou-se nos maiores mestres, en- 
tre os quaes Windscheid (o technico por excellencia) e Savigny (o immortal romanista). Polido, erudito, possuidor de uma distincção fidalga no traje e nas maneiras, incapaz de se deixar desrespeitar, energico, mas cheio de bondade, é elle o director ideal para nossa Faculdade, que é de difficil administração. Admiravel por seu tacto no espinhosissimo cargo que occupa, justifica a opinião de que nunca houve idirector que reunisse em si tantas qualidades apreciaveis e dotes tão peregrinos.

Não é de deixar em olvido que trabalhos seus foram elogiados publicamente por Vidari, um dos maiores commercialistas de que se honra a Italia.

Si, como affirma Stuart Mill, um dos aspectos mais sympathicos do caracter de Augusto Comte era sua affeição para com os animaes, suas tendencias para o zoophilismo, tão generalizadas pna culta Inglaterra, indicio é seguro da bondade do actual Director esse sentimento tầo nobre e infelizmente tão pouco vulgarizado em nosso paiz. No olhar do illustre jurisconsulto patrio nota-se aquelle in- telligentissimo, malicioso, ironico e bonidoso sorriso que observámos no de Anatolio França, quando visitou nossa Faculdade. E digno é de menção que não só pelo olhar, mas por seus traços physionomicos, por seu porte, tem elle a maior semelhança com o grande psychologo ei literato francez, que sabia unir o espirito critico á bondade, coisa summamente difficil. Conserve-o Deus por muitos annos com a mesma lucidez de espirito, com os mesmos sentimentos de nobreza e bondade que ornam sua admiravel figura, a qual, sem duvida, a muitos inspira inveja. 


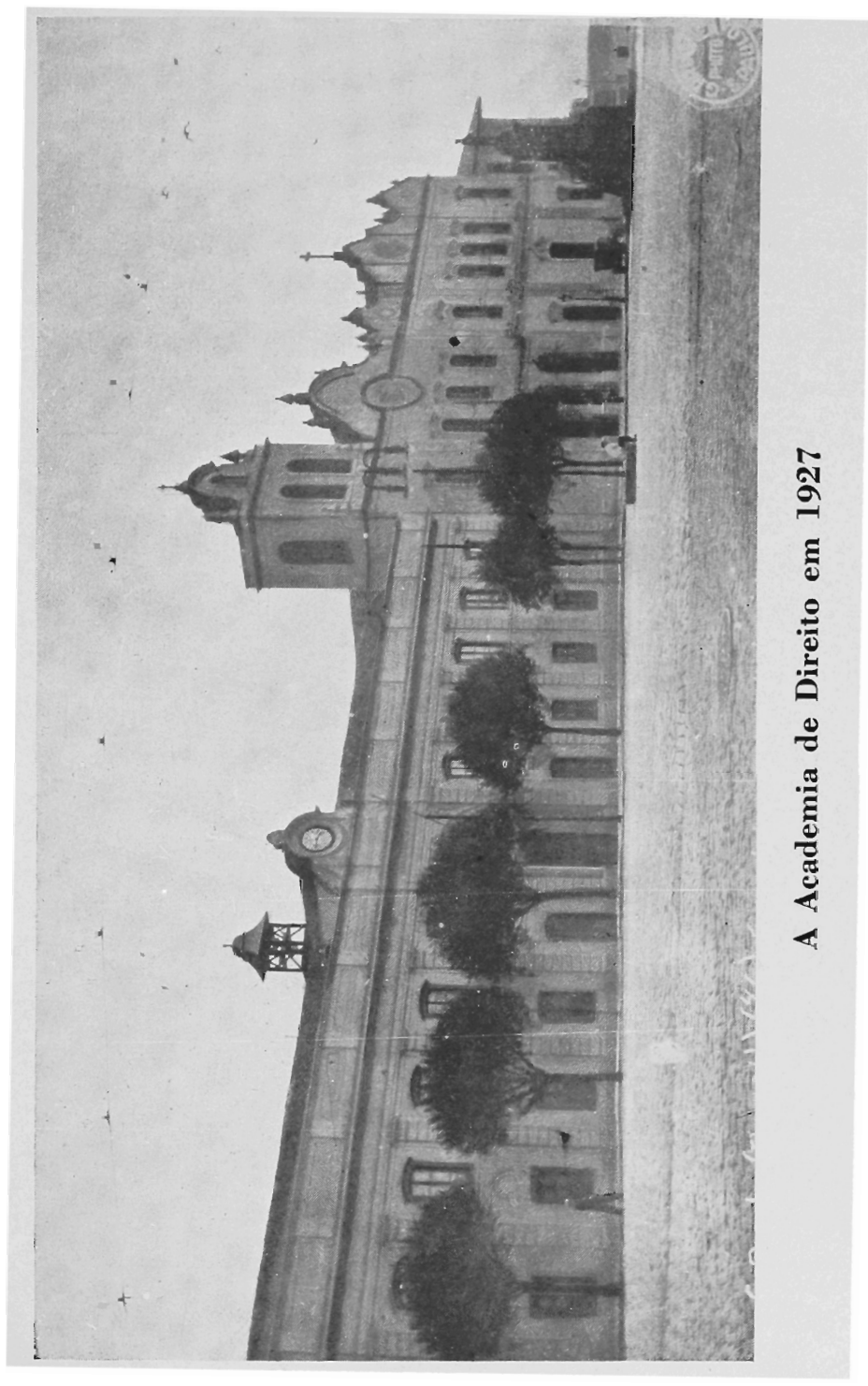



O Predio. - Tendo a escolher entre os conventos do Carmo, de São Bento e de São Francisco, foi o Governo em 1827 forçado a acceitar este ultimo por ser o unico que era assás grande para comportar o numero elevado de pessoas indispensaveis á Faculdade. Embora vasto e dotado de grandes salas, sempre foi o predio de aspecto pobre ou mesmo miseravel. As reformas foram pequenas e parciaes, só tendo havido mais alguma generalidade na feita ao tempo em que era director o Dr. Dino Bueno. Para se avaliar o que era a Faculdade pelo seu aspecto de accommodação no velho convento, basta dizer que, estando o telhado da casa, desde muito, em pessimas condições, foi problema grave chegar o Dr. Vicente Mamede a conseguir do Governo verba para reparos: e isto só foi alcançado em 1908, ou mais de 80 annos depois de estar a Faculdade alojada em uma casa onde a chuva era senhora soberana. A mais antiga photographia que se conhece do convento é a de 1862. Dá-nos uma ildea do triste estado a que o tempo reduzíra o casarão. - Com os melhoramentos successivos páde ser considerado actualmente como sendo excellente para o fim a que é destinado, dando aos professores, alumnos e empregados o conforto que pódem exigír de um estabelecimento desse genero.

Importancia da Faculdade. - De nossa Faculdade sahiram, alem dos vultos que são com frequencia citados como honrando a cultura juridica em nossa patria, uma verdadeira caravana portadora de luzes para todo o páiz. Cada juiz de direito que partia para uma comarca longinqua levava comsigo ideas liberaes, principios elevadissimos da mais pura doutrina social. Cayda advogado que ia 2 - Faculdade de Direito. 
tentar fortuna em remotas paragens era um outro foco de luz, um elemento de divulgação de boas ideas, um semeador incançavel de verdades utilissimas á nossa patria.

O bacharel em direito, contra quem se levanta a grita da ignorancia, assim como outrora clamavam os judeus contra seus prophetas e contra o proprio Christo, foi o factor mais valioso do progresso do Brasil. Confessam-no todos quando se allude a Ruy Barbosa, a Euzebio de Queiroz, mas negam-no quanido ha referencia ao modesto trabalhador, ao soldado desconhecido sem cujo auxilio o general nada pódle alcançar. E' esse soldado anonymo que deve merecer hojei nossa sympathia, não nos sendo licito esquecer de que muitos foram os que cahiram, mesmo no cumprimento do dever, feridos pelo punhal dos assassinos inimigos da ordem e do progresso.

Dr. Braz de Sousa Arruda. 